\title{
Oral Thromboprophylaxis Following Total Hip or Knee Replacement: Review and Multicentre Experience with Dabigatran Etexilate
}

\author{
D. Kendoff ${ }^{*}, 1$, C. Perka ${ }^{2}$, H. M. Fritsche ${ }^{3}$, T. Gehrke ${ }^{1}$ and R. Hube ${ }^{4}$ \\ ${ }^{I}$ Department of Orthopaedic Joint Surgery and Endoprosthetics, ENDO-Klinik Hamburg, Germany \\ ${ }^{2}$ Center for Musculoskeletal Surgery Orthopaedic Department, Charité, University Medicine Berlin, Free and \\ Humboldt-University of Berlin, Germany \\ ${ }^{3}$ Endogap Joint Replacement Institute, Klinikum Garmisch-Partenkirchen, Garmisch-Partenkirchen, Germany \\ ${ }^{4}$ Department of Orthopaedic Surgery, OCM Clinic, Munich, Germany
}

\begin{abstract}
The risk of venous thromboembolism (VTE) in patients undergoing total knee or hip replacement surgery is high. As a result, thromboprophylaxis is highly recommended. While current thromboprophylactic agents, such as low molecular weight heparins (LMWH) and vitamin $\mathrm{K}$ antagonists, are safe and effective their use can be problematic. Therefore, there is a need for alternative anticoagulants that are as safe and effective as conventional agents, but are more convenient and easier to use. Dabigatran etexilate, a direct thrombin inhibitor, is one such anticoagulant. For VTE prevention following major orthopaedic surgery, dabigatran etexilate shows similar efficacy and safety to the LMWH enoxaparin, and is approved for use in more than 75 countries, including Europe and Canada. Here, we summarize and discuss the experiences of four German clinics that have recently introduced dabigatran etexilate into clinical practice. Overall, dabigatran etexilate was well received by patients, surgeons and nurses, and compared favourably with enoxaparin. Staff appreciated the oral, single-dose administration of dabigatran etexilate. Patient satisfaction was high, especially in those individuals who had previously used LMWHs. In this review, we also address a number of questions that were asked by patients or staff; this will be of relevance to orthopaedic surgeons and nurses. We conclude that, in these four German clinics, dabigatran etexilate offered an effective oral alternative to existing thromboprophylactic agents in patients undergoing major orthopaedic surgery.
\end{abstract}

Keywords: Anticoagulant, Dabigatran etexilate, Direct thrombin inhibitor, Hip replacement surgery, Knee replacement surgery, Thromboprophylaxis.

\section{INTRODUCTION}

Despite the clear benefits of thromboprophylaxis, venous thromboembolism (VTE) remains one of the most common causes of re-hospitalization in orthopaedic surgery patients $[1,2]$. Here, we briefly review current thromboprophylaxis and report the experience of four German clinics that have implemented prophylaxis with the recently introduced oral direct thrombin inhibitor dabigatran etexilate.

\section{THE NEED FOR THROMBOPROPHYLAXIS FOLLO- WING ORTHOPAEDIC SURGERY}

Patients undergoing primary or secondary elective total hip replacement (THR) or total knee replacement (TKR) surgery have a high risk of VTE, which presents as symptomatic deep vein thrombosis or pulmonary embolism [3]. VTE may also be asymptomatic but detectable by venography. Without thromboprophylaxis $\sim 40-60 \%$ of these patients will develop objectively confirmed, hospital-acquired, asymptomatic, or symptomatic deep vein thrombosis [4]. Hence, since 1986, treatment with thromboprophylactic

*Address correspondence to this author at the ENDO-Klinik Hamburg, Holstenstr. 2, D-22767 Hamburg, Germany; Tel: +49 403197 1798; Fax: +49 403197 1963; E-mail: daniel.kendoff@endo.de agents has been recommended for patients undergoing major orthopaedic surgery [5]. Fatal pulmonary embolism occurs in 1 of every 300 patients following THR without thromboprophylaxis, although events are rare if guidelinerecommended anticoagulants are administered [4].

Postoperative VTE is associated with considerable morbidity and mortality [6-9], and the ever-increasing number of THR and TKR procedures being performed could also increase the incidence of these VTE-related events [1013]. Using statistical projections based on the increase in procedures between 1990 and 2003, it has been estimated that the demand for THR procedures in the USA could increase by $174 \%$ from 209,000 in 2005 to 572,000 by 2030 ; the demand for TKR procedures could increase by $673 \%$ from 450,000 in 2005 to 3.48 million by 2030 [12]. These estimates help to illustrate the scale of the current and future challenge of postoperative VTE prevention that also exists in Europe. In Germany, for instance, 223,000 THR and 157,000 TKR operations were conducted in 2008 [14]. Furthermore, it is predicted that in Germany and most other European countries, the number of primary and secondary total joint replacement surgeries will increase over the next few decades [14]. 


\section{THROMBOPROPHYLACTIC AGENTS}

Traditionally, thromboprophylaxis has been provided with low molecular weight heparins (LMWH) or vitamin $\mathrm{K}$ antagonists, such as phenprocoumon, acenocoumarol and warfarin. Although such medications are effective, there are several limitations associated with their use. LMWH are parenteral agents and, therefore, their administration can be problematic (especially outside the hospital environment) and may incur additional costs [15]. In addition, heparininduced thrombocytopenia can occur with LMWH, although the risk is thought to be lower with LMWH than with unfractionated heparin [16]; the incidence of heparininduced thrombocytopenia has been reported to be $0-0.9 \%$ in orthopaedic surgery patients treated with LMWH and 3$5 \%$ in those treated with unfractionated heparin [17]. The condition is associated with a risk of thrombotic events 30 times that of control populations and hence can result in considerable mortality and morbidity $[17,18]$. Warfarin and other vitamin $\mathrm{K}$ antagonists, which have tended to be used more in the USA than in Europe, require routine anticoagulation monitoring and dose adjustment, and have numerous food and drug interactions [19]. Vitamin K antagonists do, however, have a relative price advantage over LMWH.

Due to these relative drawbacks of existing therapies, there is a need for new anticoagulants that are safe, effective and overcome these challenges [15]. Two new oral antithrombotics, dabigatran etexilate and rivaroxaban, have been approved and established in clinical use within Germany for exclusive use in primary THR and TKR.

\section{Dabigatran Etexilate}

Dabigatran etexilate Pradaxa $^{\circledR}$, Boehringer Ingelheim $\mathrm{GmbH}$, Ingelheim, Germany) is a new, oral direct thrombin inhibitor. It is a prodrug that is rapidly converted into dabigatran, which has a half-life of 12-17 hours and is mainly (about 80\%) excreted renally [15, 20]. Dabigatran works by binding to the active site of free and clot-bound thrombin; as a result, thrombin's enzymatic capacity is inhibited [21, 22].

Based on successful pivotal phase III clinical trials in orthopaedic patients [23-24], dabigatran etexilate (hereafter referred to as dabigatran) is now licensed in over 75 countries, including Europe [25] and Canada [26], for VTE prevention following THR and TKR surgery. Pivotal studies showed that dabigatran demonstrated similar efficacy and safety compared with the parenteral LMWH enoxaparin, as prophylaxis following major orthopaedic surgery [23, 24], although at high doses it may be associated with gastrointestinal bleeding and dyspepsia [27]. Therefore, dabigatran provides an oral alternative to the parenteral agents (LMWH and fondaparinux). Compared with the oral vitamin $\mathrm{K}$ antagonist warfarin, which is still recommended and used widely in the USA [4], dabigatran has the potential to provide a number of benefits, including no food interactions and few drug interactions, convenient oral administration, no risk of heparin-induced thrombocytopenia, and predictable anticoagulant effects that abrogate the need for regular anticoagulation monitoring [28].

\section{Clinical Experience with Dabigatran}

As a direct result of the European pivotal studies, the recently published UK and German guidelines include the use of dabigatran or other anticoagulants such as LMWH [29]. Although dabigatran is used regularly within the German medical system, and is already advocated by a large number of clinical centres, no detailed clinical protocols or descriptions of its clinical use following THR and TKR have (to our knowledge) been described as yet. Therefore, it seems appropriate and relevant to review the use of dabigatran in clinical practice, comparing the pros and cons highlighted by this multicentre evaluation.

Representatives from four German centres have shared and discussed their clinics' experiences of introducing dabigatran into clinical practice and its routine use to date as thromboprophylaxis following primary TKA and THR, focusing on: number of patients treated and type of thromboprophylaxis provided at the centres; outcomes with dabigatran; patient satisfaction with dabigatran and staff opinion of dabigatran (Table 1). A distinct evaluation of the current use and its comparison with LMWH or warfarin included the following: efficacy; ease of use; time saving compared with subcutaneous application; patient advantages; patient satisfaction level; staff (nurse) satisfaction; occurrence of haematoma; pricing and overall complication rate. Any difficulties encountered, especially during the initial clinical implementation phase, were also recorded for each centre.

\section{Number of Patients Treated and Thromboprophylaxis Provided}

Over 7,200 patients have been treated with dabigatran at the four centres; these are: Klinik für Gelenkersatz (Garmisch-Partenkirchen); ENDO-Klinik (Hamburg); OCM Klinik (Munich); Center for Endoprosthetic and Reconstructive Joint Surgery (Charité, Berlin). At the Klinik für Gelenkersatz, over 2,500 patients received dabigatran between April 2008 and September 2010. The ENDO-Klinik treated over 1,500 patients with dabigatran between January 2009 and March 2010, while dabigatran has been in clinical use at the OCM Klinik (Munich) since July 2008, and as of May 2010 over 2,600 patients had received the drug. At the Center for Endoprosthetic and Reconstructive Joint Surgery, dabigatran was prescribed to approximately 600 patients between April 2009 and September 2010. As the four centres used dabigatran during the same time period, this warranted a multicenter evaluation. Individual center patient numbers and methods of examination and evaluation are not detailed due to their heterogeneity. However, surgeons completed a standardized questionnaire to provide the results as described and detailed in the text and in Table $\mathbf{1 .}$

Dabigatran was directly compared to enoxaparin, as enoxaparin was the standard treatment in all centers before the study. The criteria for choosing to prescribe dabigatran included: no contra-indications to therapy; no previous warfarin use; no severe bleeding disease; absence of a peridural catheter; the availability of a reduced dose for patients aged over 75 years, with renal insufficiency or receiving amiodarone therapy. The duration of treatment 
Table 1. Advantages and Disadvantages Associated with the Implementation and Use of Dabigatran in Clinical Practice, as Compared with low Molecular Weight Heparin

\begin{tabular}{|c|c|c|c|c|}
\hline & $\begin{array}{c}\text { ENDO- } \\
\text { Klinik }\end{array}$ & $\begin{array}{c}\text { OCM } \\
\text { Klinik }\end{array}$ & $\begin{array}{l}\text { Center for Endoprosthetic } \\
\text { and Reconstructive Joint Surgery }\end{array}$ & $\begin{array}{c}\text { Klinik für } \\
\text { Gelenkersatz }\end{array}$ \\
\hline \multicolumn{5}{|l|}{ Advantages } \\
\hline Good efficacy & • & • & .1 & • \\
\hline Comparable efficacy to enoxaparin & & & & • \\
\hline Ease of use/oral dosing/single application/fixed flexible dosing & • & • & .1 & • \\
\hline Time-saving & & • & & • \\
\hline Can be taken by patients at home & • & • & & • \\
\hline High patient satisfaction levels & • & • & & • \\
\hline High staff satisfaction levels & & & • &.$^{2}$ \\
\hline Lack of haematoma & & • & & - \\
\hline No risk of heparin-induced thrombocytopenia & • & • & & • \\
\hline No need for regular monitoring of coagulation parameters & • & • & & • \\
\hline No increase in DVT in first 8 days post-surgery & • & • & & • \\
\hline No increase in complications such as severe bleeding or need for wound revision & • & • & & • \\
\hline Reduced dosage available & & & & • \\
\hline Good safety profile & • & • & • & • \\
\hline Clarity of protocol & & & • & \\
\hline Fair pricing & & & • & • \\
\hline \multicolumn{5}{|l|}{ Disadvantages } \\
\hline Time-consuming implementation & • & • & & • \\
\hline Limitations during spinal anaesthesia & • & • & & • \\
\hline Not suitable for use following DVT & • & • & & • \\
\hline No indication for treatment of DVT & • & • & & • \\
\hline Relative inaccuracy of laboratory coagulation parameters & • & • & & • \\
\hline No long-term experience & • & • & & • \\
\hline Severe nausea in some patients requiring change of therapy & • & • & & • \\
\hline Possible cost disadvantage & • & & & • \\
\hline Large size of capsules & & & & - \\
\hline
\end{tabular}

- Either data provided by the clinic supports this statement or an author from the clinic stated that they agree with the statement.

${ }^{1}$ Very good; ${ }^{2}$ Mostly.

DVT, deep vein thrombosis.

with dabigatran was in accordance with European guidelines: 28-35 days for THR patients and 10 days in TKR patients [25].

The alternative thromboprophylactic agents routinely prescribed in these clinics included enoxaparin (Clexane ${ }^{\circledR}$ [Sanofi Aventis, Paris, France]), heparin (Certoparin ${ }^{\circledR}$ [Novartis, Basel, Switzerland]) and fondaparinux (Arixtra ${ }^{\circledR}$ [GlaxoSmithKline, Brentford, UK]). Patients received these alternative medications if they exhibited the contraindications listed in the package insert for dabigatran. Switching from one therapy to another occurred for several reasons. Selected patients switched to dabigatran following the removal of the peridural catheter and occasionally due to recommendations from family doctors. A switch from dabigatran to enoxaparin was also necessary for selected patients due to reports of nausea. While nausea is a common side effect of surgery/anaesthesia, switching of therapy was only needed in a small number of cases (fewer than 20 patients in the overall cohort). In addition, a small proportion of patients in three of the four centres reported a slight prolongation in wound secretion, which necessitated a switch to LMWH. However, an initial surveillance study including over 200 patients by the Endo-Klinik Hamburg did not show a significant prolongation of the incision or drainage wound when compared with LWMH.

\section{Safety and Efficacy Outcomes with Dabigatran}

All advantages and disadvantages associated with the implementation of the new drug are summarized in Table $\mathbf{1 .}$ In general, the efficacy and safety of dabigatran were 
deemed to be good or very good by the clinics and were thought to be comparable to the parenteral anticoagulants used. Since dabigatran is administered orally as a fixed dose, it was found to be easy to use. At three of the centres no notable safety complications with dabigatran were reported. However, one clinic reported rare cases of intestinal tract bleeding in patients receiving dabigatran, but a connection between the two was deemed questionable by the clinic.

\section{Patient Satisfaction with Dabigatran}

Patient satisfaction with dabigatran in these clinical settings was high, and in some centres better patient comfort was reported with dabigatran. A number of questions were frequently asked by patients, including how dabigatran's efficacy compared to that of enoxaparin, and whether one dosing regimen was suitable for all. Satisfaction with dabigatran was particularly high in those patients with previous experience of LMWH; indeed, dabigatran's oral administration was preferable to the parenteral application of LMWH, which can be associated with abdominal haematomas.

However, some patients complained about the increasing number of oral medications that they needed to take postoperatively. The extra two capsules $(2 \times 110 \mathrm{mg})$, in addition to other necessary drugs, such as painkillers and anti-inflammatory medications, increase this burden. This is particularly a problem in the early postoperative phase, which is associated with limited oral receptiveness.

\section{Staff Opinion of Dabigatran}

Although the implementation of the drug was initially time-consuming for nurses and clinical staff, the ease of use once implemented was rated as good. Staff appreciated the simple, independent and single daily dose application of dabigatran, all of which are likely to aid compliance. The fact that routine laboratory monitoring is not required was welcomed, as was the option of a reduced dose for specific patient groups.

Staff questioned the initiation and duration of dabigatran treatment and whether adjustment for body weight was necessary. It is recommended that dabigatran is initiated as a half dose 1-4 hours post-surgery if appropriate levels of haemostasis are achieved. However, if this is not possible, therapy should be started as a half dose later on during the day of surgery or as a full dose on the following day [30]. Studies show that delaying the initiation of $220 \mathrm{mg}$ dabigatran does not affect efficacy [31].

As shown in a previous study, and confirmed with our nursing experience, the two main benefits of oral administration were removal of the threat of needle-stick injuries and of the need for patient education regarding LMWH self-administration in the rehabilitation phase [32]. However, it was also highlighted by the nurses that subcutaneous drugs, administered by the nurse, might be appropriate for some very elderly patients or patients with cognitive impairment.

\section{SUMMARY}

Thromboprophylaxis is recommended following THR and TKR, and there has been a need for safe and effective but more convenient anticoagulant therapies. Dabigatran has been licensed for this indication in over 75 countries, including Europe and Canada. Here, we have documented the experiences of four German clinics that have introduced dabigatran into routine clinical practice. This was an important exercise since the implementation of, and experiences with, a drug during trial conditions may differ from those in a clinical setting. This experience with over 7,200 patients should provide useful and relevant information for surgeons considering dabigatran for the indication discussed. Overall, dabigatran was viewed as an effective oral alternative for thromboprophylaxis following major orthopaedic surgery, and its discussed advantages are likely to improve patient adherence to anticoagulant therapy. To simplify general oral VTE prophylaxis for the orthopaedic surgeon, we propose that dabigatran should also be investigated for trauma or other elective surgical interventions involving the lower extremities.

\section{ACKNOWLEDGEMENTS}

This work was supported by Boehringer Ingelheim. Writing and editorial assistance was provided by L. Godwin, $\mathrm{PhD}$ of PAREXEL, who was contracted by Boehringer Ingelheim for these services. The authors meet criteria for authorship as recommended by the International Committee of Medical Journal Editors (ICMJE) and were fully responsible for all content and editorial decisions, and were involved at all stages of manuscript development.

\section{CONFLICT OF INTEREST}

The authors are paid consultants of Boehringer Ingelheim.

\section{REFERENCES}

[1] Pellegrini VD Jr, Donaldson CT, Farber DC, Lehman EB, Evarts CM. The John Charnley Award: prevention of readmission for venous thromboembolic disease after total hip arthroplasty. Clin Orthop Relat Res 2005; 441: 56-62.

[2] Pellegrini VD Jr, Donaldson CT, Farber DC, Lehman EB, Evarts CM. The Mark Coventry Award: Prevention of readmission for venous thromboembolism after total knee arthroplasty. Clin Orthop Relat Res 2006; 452: 21-7.

[3] Agnelli G. Prevention of venous thromboembolism in surgical patients. Circulation 2004; 110(24 Suppl 1): IV4-IV12.

[4] Geerts WH, Bergqvist D, Pineo GF, et al. American College of Chest Physicians. Prevention of venous thromboembolism: American College of Chest Physicians Evidence-Based Clinical Practice Guidelines (8th Edition). Chest 2008; 133(6 Suppl): 381S453S.

[5] National Institutes of Health Consensus Conference. Prevention of venous thrombosis and pulmonary embolism. JAMA 1986; 256(6): 744-9.

[6] Heit JA, Silverstein MD, Mohr DN, Petterson TM, O'Fallon WM, Melton LJ $3^{\text {rd }}$. Predictors of survival after deep vein thrombosis and pulmonary embolism: a population-based, cohort study. Arch Intern Med 1999; 159(5): 445-53.

[7] Wille-Jørgensen P, Jorgensen LN, Crawford M. Asymptomatic postoperative deep vein thrombosis and the development of postthrombotic syndrome. A systematic review and meta-analysis. Thromb Haemost 2005; 93(2): 236-41.

[8] Sørensen HT, Horvath-Puho E, Pedersen L, Baron JA, Prandoni P. Venous thromboembolism and subsequent hospitalisation due to acute arterial cardiovascular events: a 20 -year cohort study. Lancet 2007; 370(9601): 1773-9.

[9] Lie SA, Pratt N, Ryan P, et al. Duration of the increase in early postoperative mortality after elective hip and knee replacement. J Bone Joint Surg Am 2010; 92(1): 58-63.

[10] Ostendorf M, Johnell O, Malchau H, Dhert WJ, Schrijvers AJ, Verbout AJ. The epidemiology of total hip replacement in The Netherlands and Sweden: present status and future needs. Acta Orthop Scand 2002; 73(3): 282-6. 
[11] Pedersen AB, Johnsen SP, Overgaard S, Søballe K, Sørensen HT, Lucht U. Total hip arthroplasty in Denmark: incidence of primary operations and revisions during 1996-2002 and estimated future demands. Acta Orthop 2005; 76(2): 182-9.

[12] Kurtz S, Ong K, Lau E, Mowat F, Halpern M. Projections of primary and revision hip and knee arthroplasty in the United States from 2005 to 2030. J Bone Joint Surg Am 2007; 89(4): 780-5.

[13] Culliford DJ, Maskell J, Beard DJ, Murray DW, Price AJ, Arden NK. Temporal trends in hip and knee replacement in the United Kingdom: 1991 to 2006. J Bone Joint Surg Br 2010; 92(1): 130-5.

[14] Bundesgeschäftsstelle Qualitätssicherung und Patientsicherheit, 2008. http://www.bqs-register140d.de/.

[15] Maegdefessel L, Spin JM, Azuma J, Tsao PS. New options with dabigatran etexilate in anticoagulant therapy. Vasc Health Risk Manag 2010; 6: 339-49.

[16] Warkentin TE, Greinacher A. So, does low-molecular-weight heparin cause less heparin-induced thrombocytopenia than unfractionated heparin or not? Chest 2007; 132(4): 1108-10.

[17] Arepally GM, Ortel TL. Heparin-induced thrombocytopenia. N Engl J Med 2006; 355(8): 809-17.

[18] Silver D, Kapsch DN, Tsoi EK. Heparin-induced thrombocytopenia, thrombosis, and hemorrhage. Ann Surg 1983; 198(3): 301-6.

[19] Hirsh J, Dalen J, Anderson DR, et al. Oral anticoagulants: mechanism of action, clinical effectiveness, and optimal therapeutic range. Chest 2001; 119 (1 Suppl): 8S-21S.

[20] Stangier J, Rathgen K, Stähle H, Gansser D, Roth W. The pharmacokinetics, pharmacodynamics and tolerability of dabigatran, a new oral direct thrombin inhibitor in healthy male subjects. Br J Clin Pharmacol 2007; 64(3): 292-303.

[21] Hauel NH, Nar H, Priepke H, Ries U, Stassen JM, Wienen W. Structure-based design of novel potent nonpeptide thrombin inhibitors. J Med Chem 2002; 45(9): 1757-66.

[22] Wienen W, Stassen JM, Priepke H, Ries UJ, Hauel N. In-vitro profile and ex-vivo anticoagulant activity of the direct thrombin inhibitor dabigatran and its orally active prodrug, dabigatran etexilate. Thromb Haemost 2007; 98(1): 155-62.

[23] Eriksson BI, Dahl OE, Rosencher N, et al; RE-MODEL Study Group. Oral dabigatran etexilate vs subcutaneous enoxaparin for the prevention of venous thromboembolism after total knee replacement: the RE-MODEL randomized trial. J Thromb Haemost 2007; 5(11): 2178-85.

[24] Eriksson BI, Dahl OE, Rosencher N, et al. RE-NOVATE Study Group. Dabigatran etexilate versus enoxaparin for prevention of venous thromboembolism after total hip replacement: a randomised, double-blind, non-inferiority trial. Lancet 2007; 370(9591): 949-56.

[25] EPAR Summary for the Public: Pradaxa ${ }^{\circledR}$. European Medicines Agency; 2011. Available at: http://www.ema.europa.eu/docs/en GB/d ocument library/EPAR_-_Summary_for_the public/human $/ 000829 / \mathrm{W}$ C500041060.pdf [Accessed: 7 September 2011].

[26] Pradaxa ${ }^{\circledR}$ monograph. Canada: Boehringer Ingelheim; 2010 Available at: http://www.boehringer-ingelheim.ca/en/Home/Huma n Health/Our_Products/Product Monographs/Pradax-pm.pdf [Accessed: April 11, 2011].

[27] Garnock-Jones KP. Dabigatran etexilate: a review of its use in the prevention of stroke and systemic embolism in patients with atrial fibrillation. Am J Cardiovasc Drugs 2011; 11(1): 57-72

[28] Dahl OE. Dabigatran etexilate: an oral direct thrombin inhibitor. Therapy 2008; 5: 685-95.

[29] Venous thromboembolism: reducing the risk. NICE clinical guideline 92. National Institute for Health and Clinical Excellence; 2010. Available at: http://www.nice.org.uk/nicemedia/pdf/CG92 QRG.pdf [Accessed: 7 September 2011].

[30] Pradaxa ${ }^{\circledR}$ SPC: Summary of Product Characteristics. Boehringer Ingelheim International $\mathrm{GmbH}$; 2009. Available at: http://www. ema.europa.eu/docs/en GB/document library/EPAR - Product In formation/human/000829/WC500041059.pdf [Accessed: 7 September 2011].

[31] Dahl OE, Kurth AA, Rosencher $\mathrm{N}$, et al. Delay in initiating prophylactic treatment with dabigatran etexilate following total hip or knee replacement surgery did not affect efficacy. Pooled analysis of two European phase III trials. J Thromb Haemost 2009; 7(Suppl 2): 695 Abstract PP-WE-204.

[32] Wilke T, Neumann K, Klapper U, et al. Oral anticoagulation after major hip or knee replacement surgery: a process-driven managerial pharmacoeconomic analysis in German hospitals [Article in German]. Orthopade 2008; 37(5): 448-56. 